\title{
CHALLENGES FOR THE EMERGING STOCK MARKETS
}

\section{Irina Yarygina ${ }^{1}$ Vladimir Gisin ${ }^{2}$}

DOI: https://doi.org/10.30525/978-9934-588-15-0-47

Abstract. Strengthening financial cooperation between the members of the Eurasian Economic Union is the best solution to mitigate trade wars, unfair competition and worsening of international economic relations. In this paper, we analyze and determine correlation between Eurasian stock markets, taking into consideration their reasonable interaction. The aim of the article is to introduce recommendations aimed at optimizing financial cooperation with EAEU member - states and their partners. The existing data is processed using combination of Bloomberg, Excel and Math's tools. Complex analyses in the aim of the article is presented. Testing of initial hypothesis proved strong interdependence of Moscow and Kazakh stock markets that are mostly developed and presented in data. The graphical analysis of this research concludes that the Kazakh index had a relatively weak relationship with the Moscow Index until 2007. Thereafter, the effects of the global financial crisis in 2008 affected both stock markets, resulting in becoming highly correlated. The research founds out, that the indexes of the emerging stock markets actually still rely on the production of raw materials and depends on the price movements of commodities. We consider, that it may be reasonable to take into consideration the international experience in risk management as well as conveying better access to loans for commercial entities; improving inter government grants to new industries and taxing relief for manufactured exported goods. In order to break the economic deadlock of some EAEU stock markets it is

\footnotetext{
${ }^{1}$ Doctor of Economic Sciences, Professor,

Professor at Department of World Economy and World Finance, Head of Programs,

Financial University under the Government of the Russian Federation, Russian Federation

ORCID: http://orcid.org/0000-0001-8684-1684

${ }^{2}$ Candidate of Physical and Mathematical Sciences, Professor,

Scientific Director of the Master's Program "Blockchain and Cryptocurrency Technology", Professor of the Department of Data Analysis, Decision-making and Financial Technologies,

Financial University under the Government of the Russian Federation, Russian Federation ORCID: https://orcid.org/0000-0002-7269-0587
} 
worth, while introducing harmonized financial policies that would pave the way for mutual development. In this respect, we recommend conveying better access to loans for private entities, improving government grants to new industries and technologies as well as providing taxing relief for manufactured exported goods in order to break the deadlock of non harmonized regulation and pave the way for welfare.

\section{Introduction}

Originally, establishing Eurasian Economic Union, the member-states aspired for a very simple and noble cause. They joined forces, pooled knowledge and capabilities in order to protect their sovereignty and independence more efficiently, to make their voices better heard in international and global affairs, and to foster their internal economic, political and social development based on mutual respect and recognition of their specificities. These are entirely legitimate tasks, fair and logical, compatible in all their aspects with the aims and principles of contemporary international law. Member - countries has shown that achieving these goals is feasible and attainable. Coordination of efforts, activities and policies of the member-states on a wide variety of issues produced positive impact on the international economy and finance. Nevertheless, results could have been more impressive if the cooperation among members of the Eurasian Economic Union was stronger and deeper.

Actually, the Eurasian Economic Union is an economic union consisting of the following states; Armenia, Belarus, Kazakhstan, Kyrgyzstan and Russia. The treaty came into force on the 1st January 2015. This Union provides a single market for the 183 million inhabitants of the countries. This region has a gross domestic product of $\$ 4$ trillion according to The World Bank. The single market provides, free movement of goods, capital, services and people. It also allows each member to use common policies in for their macroeconomic sectors such as, transport, industry, technical regulation, agricultural, energy, foreign trade and investment and competition.

Provisions for a single currency and greater integration are envisioned for the future [1]. The day to day work of the Union is performed by the Eurasian Economic Commission which is similar to the European commission. The main purpose of the union is to establish and open up economic development between the countries. Great attention is payed to the Stock markets and its possible alliances. 
Practice has shown, that creation and development of firms exchanging their products and services within the framework of mutual trade and financial relations between the countries of Eurasian Economic Union lay at the basic of the mutual influence of these countries stock markets and indices. Therefore, we have started with the assessment of the volume dynamics of mutual trade between the EAEU countries and researched how the macroeconomic indicator changed. Then we compared the stock indices of Russia, Armenia, Belarus, Kazakhstan and Kyrgyzstan. 2000 year was taken as the initial year of our measurement. It was the year, preceding the creation of the Eurasian Economic Community. Despite the fact that there was no Armenia among the members of the EAEC from the very beginning of its existence, we include it in our statistics. Armenia has the status of observer from 2003. Such choice was dictated by the desire to make our statistical sample more representative. The last year of our measurement is mostly 2017. The research considers the trade turnover of goods and services between all five countries that constitute EAEU. If data is available the indices of 2018 are also presented.

As there is no data available on the Armenian, Belarus and Kyrgyzstan stock markets, therefore, our research paper comprises of the final two countries; analysis of one minor Eurasian stock market the KZKAK (Kazakhstan) against one major stock market the MCX (Moscow). Enforcement of the relations between stock markets is important for a number of reasons. The relationship can have both positive and negative effects on fiscal and monetary policies. According to Gavin, a stock market which is booming can positively affect aggregate demand [2]. This justifies the relevance of this research.

The two countries are neighbors which reflects their high trade to one another. Russia is the second largest receiver of exports from Kazakhstan consisting of $11.8 \%$ while Kazakhstan is the 10th largest receiver of exports from Russia consisting of 3.1\%. Furthermore, the market capital size of the MCX index is reported by Bloomberg to be $\$ 9.97$ trillion, while the KASE index is $\$ 346.59$ billion. This suggests that the MCX is the major index while KASE is the minor index. The study is conducted to establish the relationship between the two countries and their interdependence of one another. The stock markets are compared along with the major groups in each market to obtain an understanding of the structure of the indices and to explain a high correlation that exists between the two markets. 
The structure of this project begins with a brief literature review to identify previous related research conducted in this area. Following this is the methodology. Then, a graphical analysis which includes a detailed analysis of the Eurasian markets followed by separate external analysis using a European and United States index to find external impacts on the Eurasian markets. This is then followed by the calculations, as well as recommendations on financial risk management to the participants of the EAEU stock markets.

\section{Literature review}

Researchers, Jochum, Kirchgassner and Platek performed a study on the consequences of the financial crisis of 1998 relating to Eastern European stock markets, including Russia (ROS). They concluded that there was a striking difference between the stock markets of Eastern Europe and Asian economies. The research found that this was due to significant influence from political and economic shifts in Russia.

When investigating the volatility of eastern European countries, Rockinger and Urga used stock markets of the Czech Republic (PX50), Poland (WIG), Hungary (BUX) and Russia (ROS) [4]. They studied these stock markets by using a comparative analysis using the FTSE100 of the United Kingdom as a benchmark. The results found that shocks in the FTSE100 are mostly positively related to the markets in the Czech Republic and Poland. The shocks were not responsive to the Russian or Hungarian markets.

In a more recent study, the long run relationship between stock markets using daily data of the US (S\&P), Germany (DAX), Russia (MCX), Hungary (BUX), Czech Republic (PI50) and Poland (WIG) was conducted by J. Yang. This study concentrated on the Russian crisis of 1998, where the results show a strengthening of the Russian market thereafter.

A favorable exchange rate can be the cause of increased exports out of a country. Economic theory suggests that when a country's exchange rate declines in value against the currency of another country, this may increase the demand for goods from a country with the weakening currency. Therefore, as exports increase, resulting in the higher revenue intake from exporting companies may reflect higher stock trends due to stronger balance sheet performances. Neih and Lee explain that exchange rates and stock markets can be an important role in the development of an economy [6]. In the case of the Russian economy, the Ruble suffered two major weakening in 2008 and 2014. It is argued that 
external forces were the major factor of this decline as foreign sanctions caused a decrease in Russian oil exports, resulting in an increase in domestic goods prices while the country's GDP declined [7]. Although, this minor study may reveal some interesting developments, it is important to note that some economists in the past have found that there is no significant relationship between exchange rates and equity prices [8]. Therefore, the exchange rates for each country will be excluded from this analysis.

With many studies available that have previously observed the stock markets of Eastern European countries and Russia, there remains a gap in available research between the stock markets of Eurasian countries. As there is no available information for Belarus, this research focuses primarily on the Russian stock market (MCX) and the Kazak stock market (KASE).

\section{Methodology}

The data collected consists of daily data of the prices for the internal study of the Kazakhstan (KASE) and Moscow (MCX) stock indices and includes an external study of the German (DAX), United Stated (S\&P500) stock indices. The daily data ranges from the beginning of the Kazak stock market on the 12th July 2000 to November 2017. Bloomberg is widely used to collect the data. The data is processed true a combination of Bloomberg and Excel in order to produce the most accurate and correct results.

The initial equation for the paper is outlined below:

$$
M C X=\beta_{0}+\beta_{1}^{*} K A S E+\varepsilon_{t}
$$

Where:

$$
\begin{gathered}
\varepsilon=\text { Error Term } \\
t=\text { Time Series Daily Data }
\end{gathered}
$$

It is concluded that each variable is stationary in returns. Hence, an Ordinary Least Squares (OLS) regression is not adequate due to the use of data in levels.

Hypothesis Testing:

To prove that there is an interdependence of the Moscow stock market as the major index and the Kazak stock market is the minor index [9]. In order to prove that this statement is correct, the research will present a correlation where:

Ho: Corr $(\mathrm{M}, \mathrm{K})>0.7$

0.7 is taken, as correlation so if this figure is above can be deemed to have a strong uphill (positive) linear relationship. 


\section{Graphical analysis: an internal analysis}

The first step is to interpret and analyze the graphs with the main aim of identifying behavior and trends of the data during the chosen period. Graphs are tools that are good to form an initial idea of the behavior of each data set. Bloomberg provides several types of graphs to identify facts quicker and logically. As the most suitable tool for this kind of data, this research consists of line charts alone.

Beginning with the stock indices that are the primary focus of the study between Russia (MCX) in solid and Kazakhstan (KASE) in long dash. It is evident that the markets are somewhat independent of one another until mid-2016. A major factor of this is the significant fact that the KASE index only consisted of seven companies groups before 2006. The initial acceleration of the KASE index is a result of the inclusion of a new group, KAZ Minerals PLC, who now accounts for $41.09 \%$ of the weighted share of the index (Figure 2). The indices are at high levels from 2006 until the beginning of the Great Recession in 2008. The high levels correspond with global stock markets that went soaring before their eventual collapse. The global recession is a contagion effect that is evident in northern hemisphere stock markets. This period saw in MCX decline by $73.74 \%$ and the KASE by $78.28 \%$ as investors lost faith in the markets. After this period, the two indexes remain highly correlated as can be seen in Figure 1.

The Flash Crash of 2010 indicated on the above graph is an event that effected stock markets across the world, starting with the US markets. The event had a substantial impact on both the MCX reducing its value by $20 \%$ and the KASE by $29.45 \%$ [10].

Another significant drop in both indices hitting lows on the 25th May 2012, where it is reported that the price of oil hit a 7-month low, two days previous [11]. The MCX dropped by $22.94 \%$ and the KASE by $23.15 \%$ during this period.

Also of further interest is the movement of the stock markets from the start of the Ukrainian political crisis in February 2014 and the sanctions that followed beginning in March. The string of events and sanctions during this period appear to have to long-term impact.

The final peak in each variable, beginning on the $8^{\text {th }}$ of November 2016, is the response from the result of the US presidential election that saw Trump as the victor. The election result was a response to the potential softening 
of relations between the US and Russia. This saw the MCX increase by $14.48 \%$ and the KASE by $21.23 \%$. Eventually the optimism seized with the MCX declining in January 2017 and the KASE remained somewhat stagnant. Both indexes reacted positively to the election.

Table 1

Industrial structure of the KASE index

\begin{tabular}{|c|c|c|c|c|c|}
\hline Sector & Mining & Oil & Banking & Communications & Electricity \\
\hline $\begin{array}{c}\text { Weight of } \\
\text { shares (\%) }\end{array}$ & 41,09 & 21,66 & 14,24 & 16,57 & 6,45 \\
\hline
\end{tabular}

Source: Bloomberg Terminal

The figure above shows information retrieved from Bloomberg, containing the members of the KASE index which reveals interesting facts that help to determine the movements of the stock market. The most interesting statistics is the fact that $21.66 \%$ of the stock market share depends on oil companies that are mostly privately owned. With the inclusion of the copper mining company Kaz Minerals, the total weight for companies involved in the production of raw materials is $62.75 \%$. This statistic is a reflection of how changes in oil or copper prices will have an impact on the movement of the KASE index, before considering macroeconomic reasons.

Actually, there are 50 companies that make up the MCX. The division of index by industrial sectors is presented in Table 2 .

This information was retrieved from the Moscow Stock Exchange, which released this data on the 22 ${ }^{\text {nd }}$ September 2017 (Moscow Exchange, 2017). From the groups listed above oil based groups represent $43.35 \%$ of the index. In February 2017 it was suggested that Russia was the biggest producer of oil in the world [12]. Including the mining industries, this figure further increases to $55.06 \%$ of the market weight. This figure is just below $20 \%$ of the KASE index but still represents a strong dependence on the production of raw materials. Where the price changes in commodities may impact the movement of the market.

For relevance it is important to find the relationship between the largest groups in each index and comparing them by a correlation using excel. Three largest sectors in each index are oil, finance (banking) and mining. Therefore, the three largest companies in each sector of each index are used for a comparative study. These companies include: the Kazakh mining 


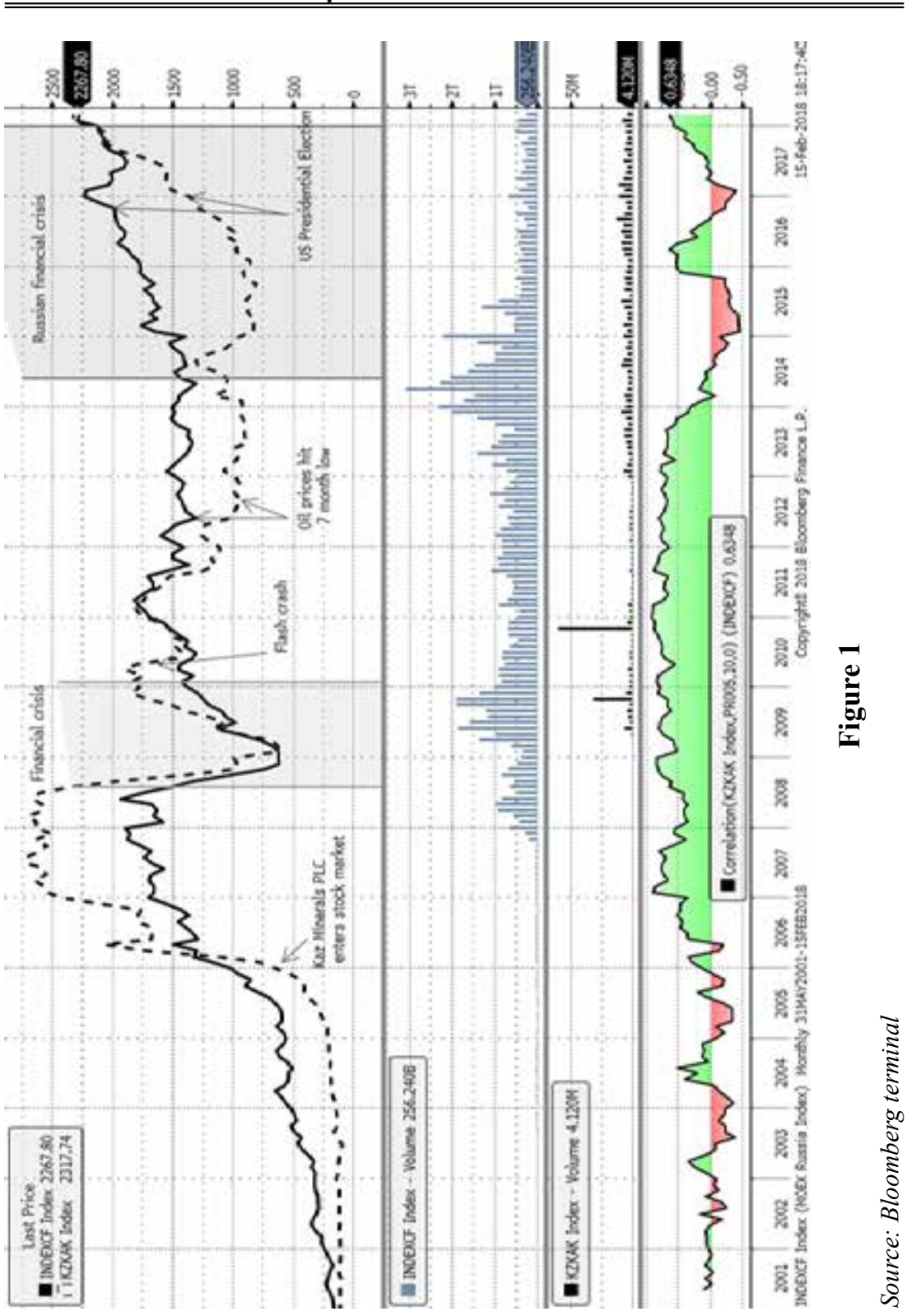


Table 2

Industrial structure of the MCX

\begin{tabular}{|c|c|c|c|c|c|c|c|}
\hline Sector & Mining & Oil & Finance & $\begin{array}{c}\text { Commu- } \\
\text { nications }\end{array}$ & Retail & Steel & Electricity \\
\hline $\begin{array}{c}\text { Weight } \\
\text { of shares } \\
(\%)\end{array}$ & 10,23 & 43,35 & 20,25 & 5,23 & 7,73 & 3,78 & 3,3 \\
\hline Sector & $\begin{array}{c}\text { Trans- } \\
\text { port }\end{array}$ & $\begin{array}{c}\text { Beve- } \\
\text { rages }\end{array}$ & $\begin{array}{c}\text { Chemi- } \\
\text { cal }\end{array}$ & $\begin{array}{c}\text { Construc- } \\
\text { tion }\end{array}$ & $\begin{array}{c}\text { Conglo- } \\
\text { merate }\end{array}$ & $\begin{array}{c}\text { Manu- } \\
\text { facturing }\end{array}$ & $\begin{array}{c}\text { Agri- } \\
\text { culture }\end{array}$ \\
\hline $\begin{array}{c}\text { Weight } \\
\text { of shares } \\
(\%)\end{array}$ & 2,12 & 0,88 & 0,99 & 0,95 & 0,44 & 0,53 & 0,22 \\
\hline
\end{tabular}

Source: Moscow Stock Exchange

company KAZ Minerals PLC and Russian Mining company Nornickel, Kazakh oil and gas company KAZ MunaiGas and Russian oils and gas company Gazprom, Kazakh banking group Halyuk Savings Bank and Russian banking group Sberbank. This will assist in determining the importance and reliance that the companies have one on another. The table below represents the correlation results of company's price movements from major industrial groups, followed by the analysis.

Table 3

\section{Correlations of price movements}

\begin{tabular}{|l|c|c|c|}
\hline \multicolumn{1}{r|}{ Russian Groups } & Nornickel & Gazprom & Sberbank \\
Kazakhstan Groups & & & \\
\hline KAZ Minerals & -0.1124 & & \\
\hline KAZ MunaiGas & & 0.4082 & 0.7183 \\
\hline Halyuk Savings Bank & & & \\
\hline
\end{tabular}

Source: Bloomberg Terminal. Data Processed using Excel

Starting off the analysis is the mining companies KAZ Minerals from the KASE index and Nornickel from the MCX index. As can be seen from the table, the two groups have a negative correlation. This can be determined by the fact that KAZ minerals is a copper mining operation, while Nornickel is predominately a nickel and palladium mining operation. Although they are in the same operating sector, both companies most likely rely on the price 
movements of their relevant metal markets for revenue. This explains the negative correlation between these two groups' stock prices.

The second correlation is focused on the oil industry. This features KAZ MunaiGas from the KASE and Gazprom from the MCX. The two groups have a moderately positive relationship. This is a reflection that both produce oil and gas to the same markets. The reason that they are not as positively correlated as expected, can be down to the fact that each company has different contracts to different countries.

The final correlation is in banking sector. The groups include Halyuk Savings bank from the KASE index and Sberbank from the MCX. The banks are shown to have a strong linear relationship. Reasoning for this strong correlation can begin by observing the banks credit ratings by the credit agencies. The Halyuk bank has a BB rating, while the Sberbank rating is Ba1 [13]. Both ratings fall in the speculative grade with nothing separating them. This suggests that investors have no incentives to pick one over the other, in terms of return, which may be the cause for their relatively close price movements.

From this analysis, it is concluded that the largest mining companies are negatively correlated as they produce different raw materials. The two largest oil and gas companies from each market are moderately correlated as they produce the same outputs. The two largest banking groups are strongly correlated as they have the same credit ratings which make them inseparable to each other for investors.

\section{Graphical analysis: an external analysis}

Our external analyses considers the trade turnover of goods and services between all five members - countries. The graphical result of this study is given in Figure 2.

Where abbreviation of KzKr means Kazakhstan - Kyrgyzstan, BKr means Belarus- Kyrgyzstan, A means Armenia, R means Russia.

Because of great difference in magnitudes of countries turnovers, given in millions of United States dollars it is reasonable to consider in one graph only relatively close to each other countries indicators. Such way we got the group of RKz and RB trade turnovers (Figure 3).

As it is obvious from the figure, given above, the dynamics of mutual trade between Russia and Kazakhstan, Russia and Belarus behave almost the 


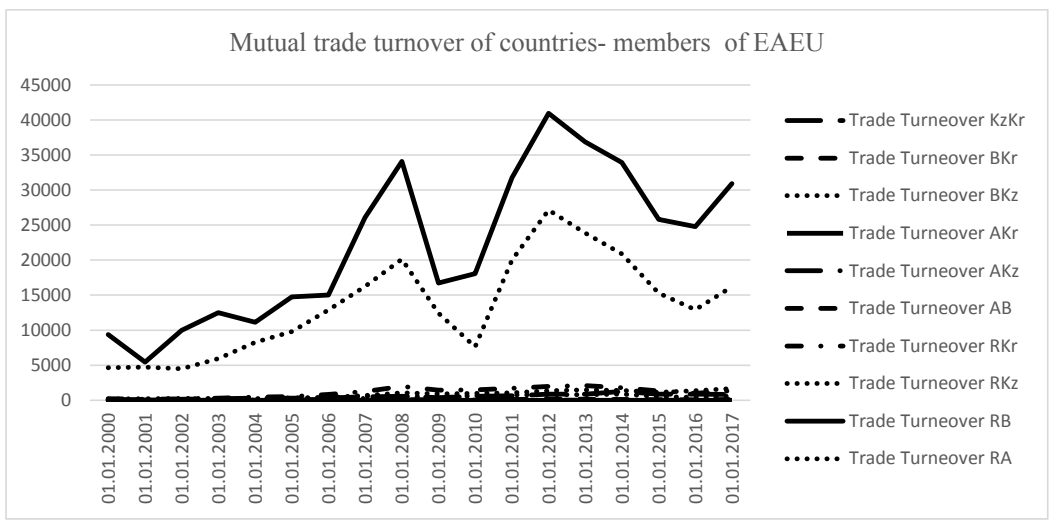

Figure 2. Mutual trade turnover of countries members of EAEU

Source: The authors' calculations based on data information and analytics system Bloomberg. The date of reference is 01.09.2018

same way with slight difference in magnitude. There are two falls stipulated by crisis of 2008 and introductions of anti-Russian suctions in 2014. Of course, their display has certain time lag. The creation of EAEU can explain the further rise of considered indicators, but the number of observations is insufficient for such conclusion yet.

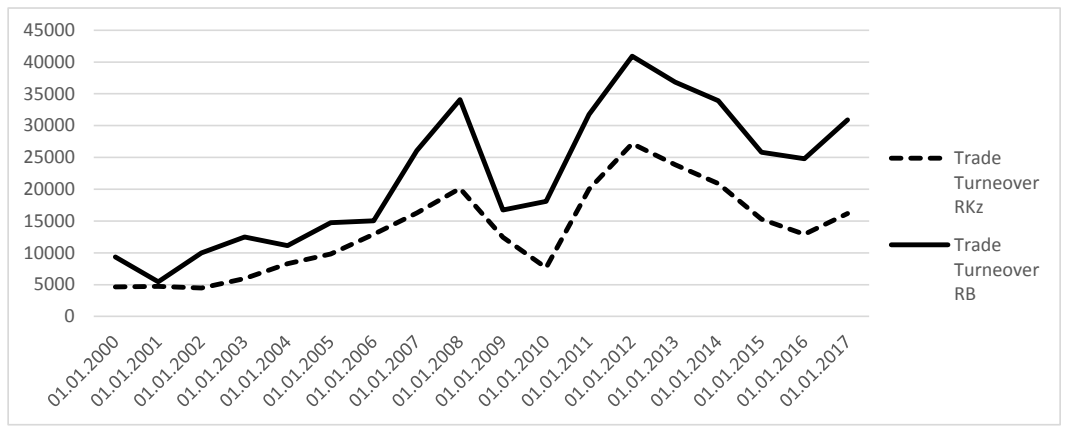

Figure 3. The highest trade turnover group of countries ( $\mathrm{mln} . \$$ )

Source: The authors' calculations based on data information and analytics system Bloomberg. The date of reference is 01.09.2018 
The other interesting group for study is group, consisting from figures of trade turnover between Kazakhstan and Kyrgyzstan, Belarus and Kazakhstan, Russia and Kyrgyzstan, Russia and Armenia (Figure 4).

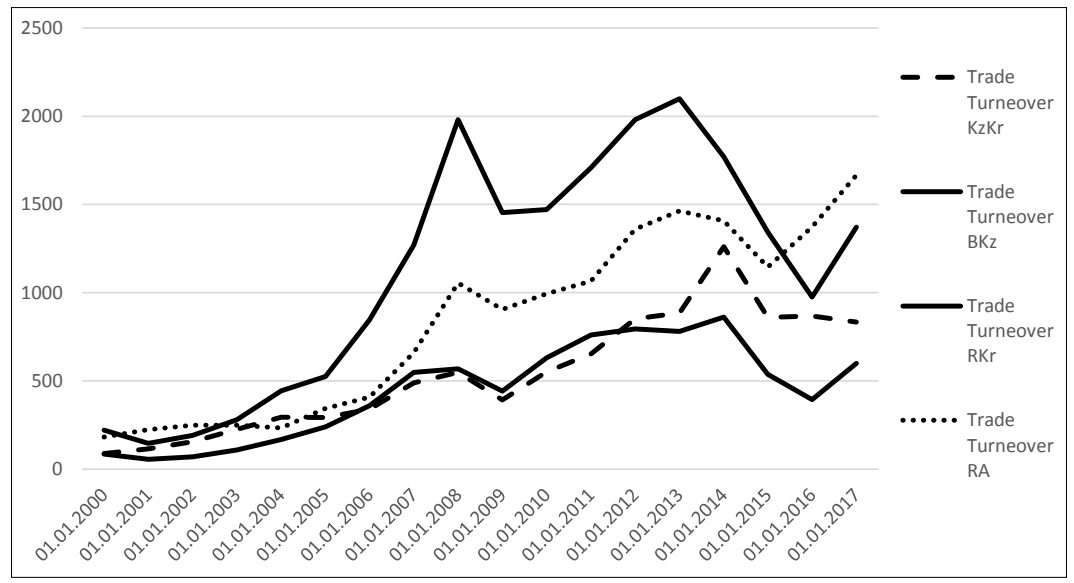

Figure 4. The second trade turnover group of countries ( $\mathrm{mln}$. \$)

Source: The authors' calculations based on data information and analytics system Bloomberg. The date of reference is 01.09.2018

The graph shows the same character of interdependence, the rises and fall, the last two years' growth in value. Only relationship between Kazakhstan and Kyrgyzstan avoids the last mentioned tendency. As for behavior of turnovers between Armenia and Kyrgyzstan, Armenia and Kazakhstan, they showed no correlation in their development.

The position in the list of trading partner has the big potential to growth. Only Russia hold the first places toward its partners (except Kyrgyzstan, where Russia is second in list). Other countries are on positions of third, even seven decade of trading partner for each other (Kyrgyzstan is the $76^{\text {th }}$ partner for Armenia; Armenia is $80^{\text {th }}$ in list for Kazakhstan). Of course, it can be partly explained by the countries' economies sizes. Nevertheless, the places were better in previous years.

All the indicators show the necessity of more close cooperation, of restoring the level of companies' integration that will lead to deeper correlation of stock indices of countries- members of EAEU. 
The analysis of the Eurasian indexes with the inclusion of two indices from the USA (S\&P500) and Germany (DAX) focuses on events which caused large movements in the external markets and determine whether they had a contagion effect on the Eurasian markets. Figure 8 shows the MCX in solid line and the S\&P500 in long dash line. On an initial observation, the MCX index has greater fluctuations compared to the S\&P while they are heavily correlated at all times. As can be seen in first shaded area of the solid lanes graph on upper screen of Figure 5, the S\&P is on a downward trend, which reflects the crash of the dot-com bubble, when the stock markets in the US suffered from excessive speculation as a result of extreme growth of the internet. The MCX was not affected by this event, since it consists of few technological companies, and it continued in an upward trend while the S\&P declined.

Both indices are affected by the financial crisis, which began with the collapse of the Lehman Brothers in September 2008. Initially the MCX was on a downward trend before the crisis evidently caused the S\&P to collapse. This situation is reflected in second shaded area of upper screen in Figure 5.

The recent strong upward trend in the S\&P has been determined by some economists as a big move by American companies to buy back their own stock as borrowing costs were ultralow [14]. The figure reported from the buyback of shares is in the region of $\$ 4$ trillion [15]. The same cannot be said for the MCX as some of the groups listed are predominantly state owned and borrowing costs are not as cheap. Therefore, analyzing the data of the recent information is difficult to inspect.

Figure 6 shows the KASE index in solid line and the S\&P shown again in long dash line. On the first observation, it is clear that the KASE index is not affected by the dot-com crash as it is a relatively new index, which had no technological companies listed on their index. Before the financial crisis the indices are negatively correlated. This fact changes as both indexes plummet with global indexes during the financial crisis. The shocks and highs of each index do not appear to follow a significant trend to one another. Apart from the beginning of 2016 when both indexes fall due to a drop in Chinese equities and oil prices at 12-year lows [16].

Following Figure 7 displays the MCX index in solid and the DAX index in long dash. On an initial observation, it is clear that both indices have a familiar trend. The correlation of both is high throughout the entire data 
set. Familiarly, the dot-com crash can be seen at the beginning of the time period with the DAX in a downward trend and the MCX remaining largely unaffected.

Fears of a US recession (Landler and Timmons, 2008) caused a shock in both indexes in January 2008, before the ultimate decline of both markets which had a greater impact on the DAX. This caused the MCX to drop by $18.49 \%$ and the DAX by $20.18 \%$.

After the financial crisis, both indices gradually increase before they are both impacted by the European sovereign debt crisis, when credit rating agencies warned for the down grade of credit ratings of 15 European countries [17]. The MCX dropped by $17.25 \%$ and the DAX by $23.57 \%$.

Following on, the next significant drop that affects both markets takes place in October 2014 as growth fears increase with falling inflation and disappointing US economic data sent shares falling across the EU and the US [18]. Again, in August 2015 the indexes suffered a contagion effect when a large drop in Asian Equities caused a panic in the markets in Europe and the US [19].

Figure 8 at the previous page contains the data of the KASE index in solid line along with the DAX index in long dash line. The first observation shows that the KASE index is somewhat not affected by the DAX until January 2006, similarly to the S\&P. The correlation is rather weak in the pre-crisis period but strengthens afterwards.

Both indices suffered during the financial crisis. There are few shocks from the DAX index that passed to the KASE index apart from the European sovereign crisis which saw a significant drop in both, effecting the KASE by $21.87 \%$ and the DAX by $23.57 \%$.

\section{Calculations}

This section includes the percentage changes that were obtained for the graph analysis. The equation of the index' value change for the table in Figure 12, given below is:

Where:

$$
\Delta_{\mathrm{MCX}}=\left(V \mathrm{f}-V_{\mathrm{i}}\right) / V_{\mathbf{1}}
$$

$V \mathrm{f}=$ Index value at the end of considered period

$V_{1}=$ Index value at the begining of considered period 


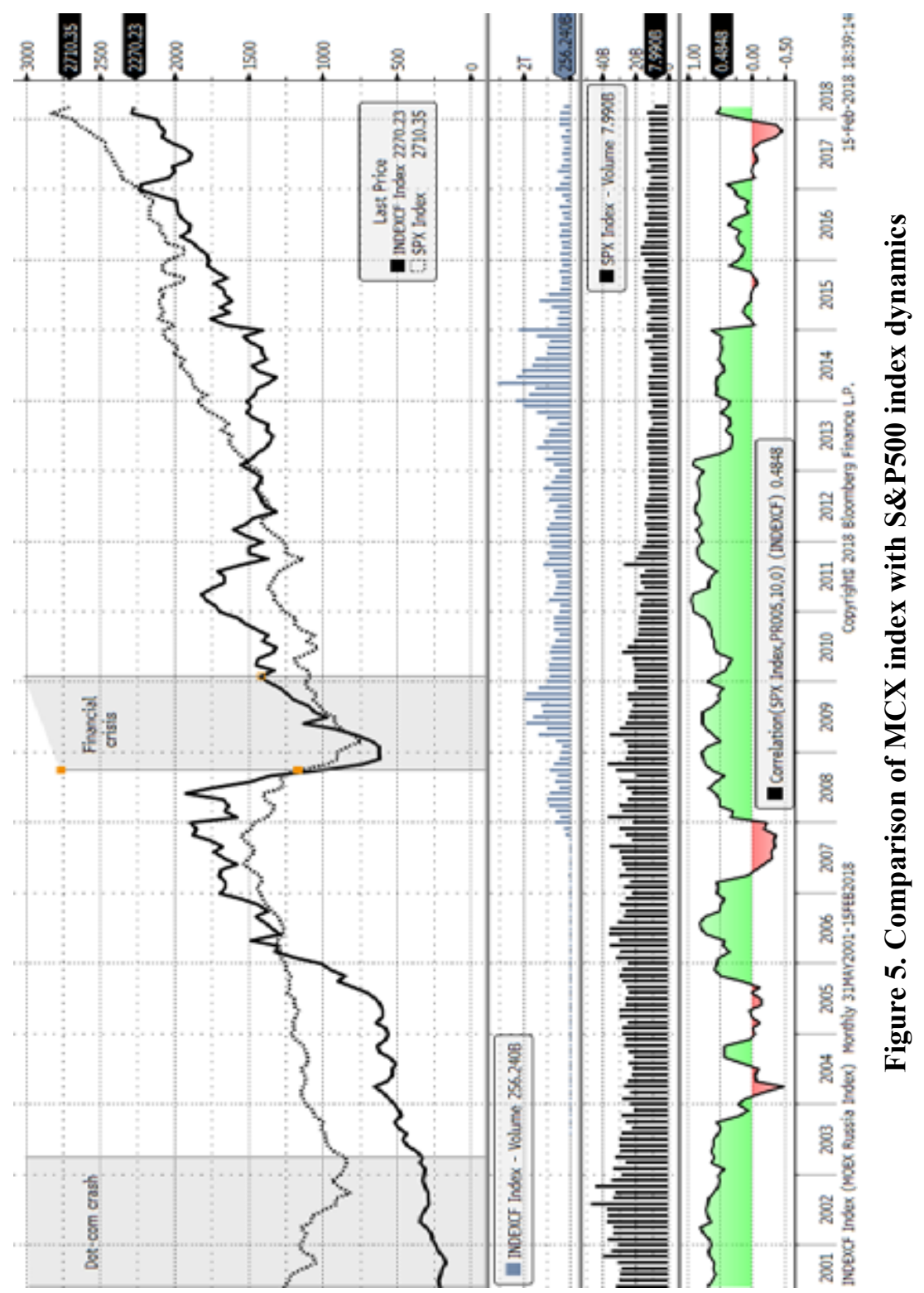




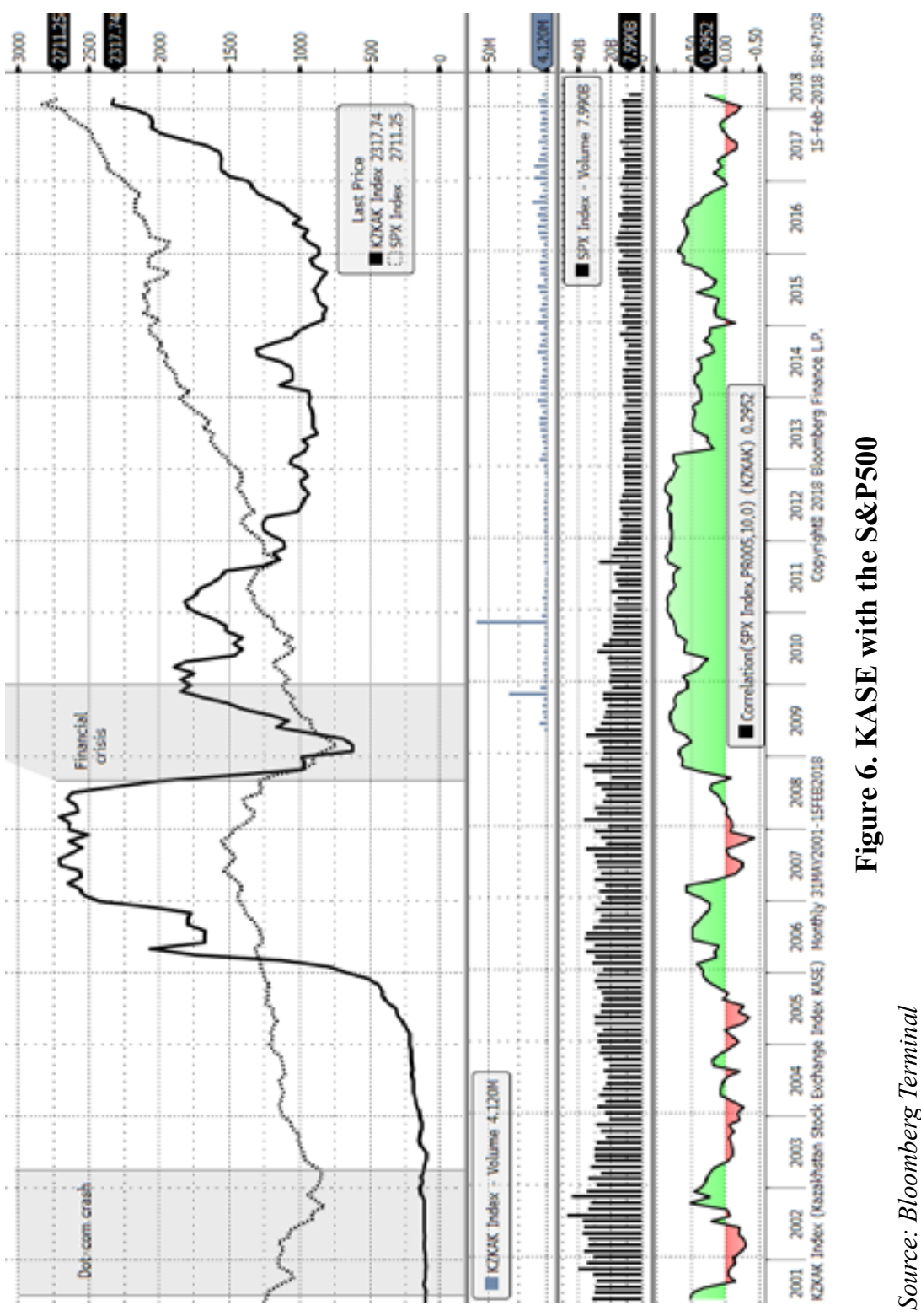


Irina Yarygina, Vladimir Gisin

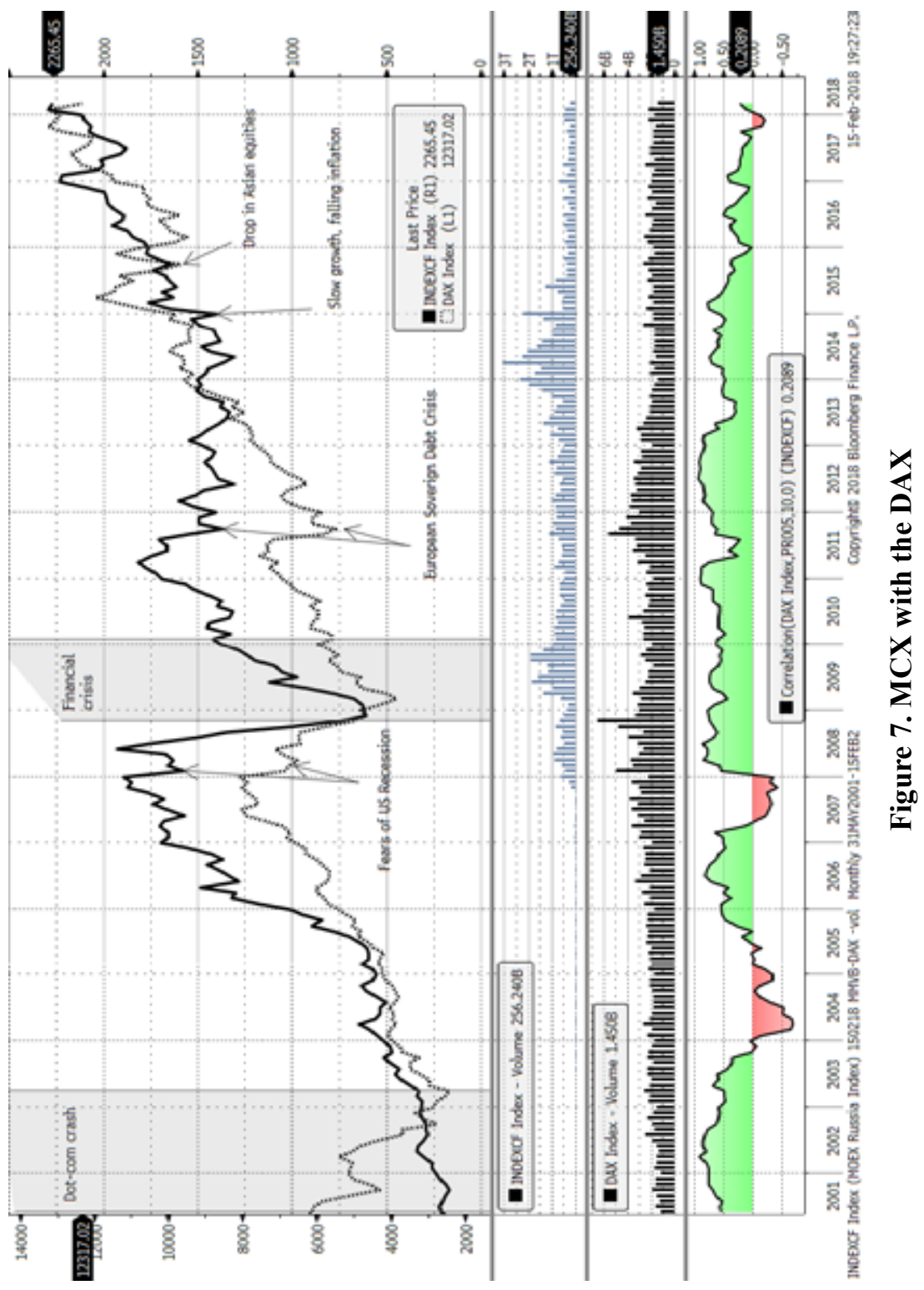


Chapter «Economic sciences»

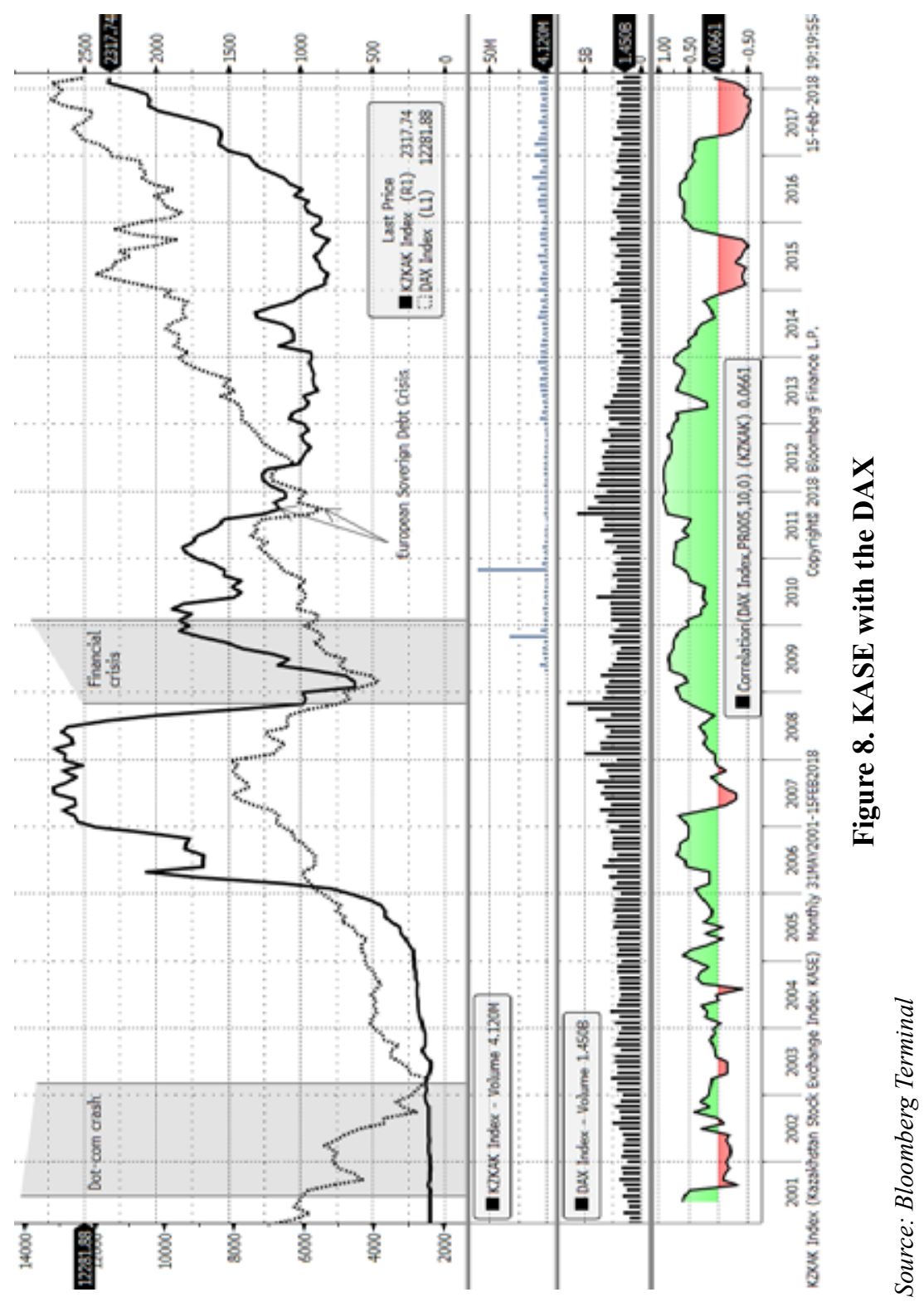




\section{Changes of MCX and KASE indices movements} under external shocks $(\%)$

\begin{tabular}{|c|c|c|c|c|c|c|}
\hline External shock & 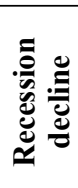 & 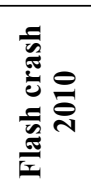 & 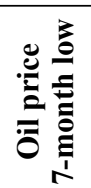 & S2 & 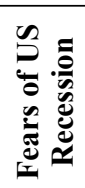 & 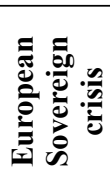 \\
\hline MCX & 73.74 & 20 & 22.99 & 14.48 & 18.49 & 21.87 \\
\hline KASE & 78.28 & 29.45 & 23.15 & 21.23 & 20.18 & 23.57 \\
\hline
\end{tabular}

Source: Bloomberg Terminal

The calculations show that, when an external shock occurs in any stock market, the markets will decrease at a substantially close level, indicating that there is a strong case for contagion effects between the relevant markets.

The final calculation represents the correlation result of the two main indices of this study, the MCX and KASE. Sought coefficient is 0.785943 . As the high correlation is above the Hypothesis of $70 \%$, the Null hypothesis can be accepted. This indicates that there is interdependence between the two stock markets. This correlation is proved by data values taken from Bloomberg. This data was then cleared to remove weekend, holiday and unmatched figures using Excel. The data is daily, ranging from the beginning of the KASE index on the $12^{\text {th }}$ July 2000 until November 2017. This consists of over 17 years of data. The calculation uses no lags as they are not relevant to this research method. The industries represented in the KASE consists of energy, banking, electricity and mining companies, while the MCX consists of energy, banking, mining, retail, technology, transport, electricity and steel. The KASE index represents 9 groups while the MCX consists of 50 groups.

\section{Recommendations for developing economies}

It may be reasonable to take into consideration international experience, that has shown that one of the main causes of the financial and economic crisis are mistakes in the financial risks management, backed by assets and liabilities of financial institutions, which remain key participants of stock markets. Financial institutions - special enterprises - carry out a wide range 
of operations on behalf of clients and at their own expense in order to make a profit. Sustainable activity of enterprises is based on compliance with the basic principles of financial risk management. The main goal of the risk management $(\mathrm{RM})$ policy is to reduce the negative impact of the economic and financial markets volatility. It does not matter whether this effect is regional or global. The set of actions to achieve enterprise RM objectives is: to analyze and evaluate the risks of operations for attracting, placing and moving funds; to carry out a qualitative and quantitative (taking into account mathematical models) assessment of the potential impact of various risks on activities and the state of liquidity; to develop and implement measures aimed at reducing the influence of risks on the results of individual operations and on the activity as a whole; to implement regulations and use models provided the qualified forecast and risk management.

The enterprise's risk assessment and risk management activities are aimed at ensuring the safe and reliable funds distribution, as well as increasing the profitability of operations, within the requirements of regulators and supervisors. Our research has introduce methods of minimizing the risks of financial operations using mathematical modeling, the Meixner Distribution and the stochastic dominance approach. Let us dwell on this issue in more detail. The analysis of financial time series, intensively carried out in the last decade especially, revealed a number of their stylized facts: heavy tails of distributions, long-term memory, volatility clustering, multifractality, etc. (see $[20 ; 21 ; 22 ; 23]$ ). The use of classical models without taking into account these features leads to a lack of accuracy in the assessment of derivative instruments, an underestimation of the extreme events probability (a sharp rise or fall in the price of risky assets) and excessive cost of risk hedging strategies. Rejection the assumption of log-returns normal distribution (a key assumption of the Black-Scholes model) allows one to obtain models more adequately describing real stock markets. It is advisable to carry out not only a quantitative, but also a qualitative assessment of the financial transactions risks based on integrated approach to determining the likelihood of losses. The financial result is affected by the economic situation of the country of operations. When assessing country risk, financial institution proceeds from the analysis of the macroeconomic indicators dynamics. It takes into account the results of monetary and financial situation analysis, inflation, budget conditions, trade and balance of payments, external debt, foreign 
exchange reserves, changes in prices for strategic goods, capital migration, changes in legislation, policies, indicators of leading rating agencies, etc. The forecast of a speculative operation is based on comprehensive analysis of the assets quality: their size, type, volume, dynamics and concentration of balance sheet assets and balance assets, source of income, as well as the impact of market factors on profit. Quantitative risk assessment includes the following performance indicators: liquidity (instantaneous and total), capital adequacy, total active operations and profitability. In some cases, yield distributions based on statistical data have characteristic indicators distinguishing them from the normal distribution. These indicators include heavy tails and asymmetry. To estimate the deviation from normality by the first indicator, the coefficient of kurtosis is used. The second indicator is the asymmetry coefficient. For example, the asymmetry coefficient calculated for a number of leading indices (S \& P 500, Nasdaq-Composite, DAX, CAC$40, \mathrm{SMI})$ ranges from -0.1 to -0.5 , the kurtosis - in interval from 1,63 to 4.17 (see [24]). For the RTS index the coefficient of kurtosis is significantly positive and is +8.44 , the coefficient of asymmetry is negative and equal to 0.46 (daily data for the period from 2000 to 2011 are used). This is consistent with the concepts known about the US and European markets. According to the results of testing the most liquid assets of the Russian stock market the hypothesis of normality can be accepted in relation to the shares of VTB, Lukoil and Norilsk Nickel only. The obtained results confirm the necessity of using the considered methodology by enterprises and the Bank of Russia. It is important to note that the observed Gaussian violations in modern conditions make us look for more flexible models of price dynamics. One of the lessons of the recent financial crisis is: Gaussian distributions (in particular, Gaussian copulas) are not able to adequately describe the relationship between the tails of profitability distributions, and therefore are not able to catch systemic risks. In this case, it is necessary to evaluate the indicators of macro-financial instability: indicators of financial stresses based on balance sheet data and selected market indicators; indicators of the so-called early warning; stress testing results. When using indicators of mathematical modeling and maintaining the assumption of independence of price increments - the main source of profit - there is a strong argument that suitable distributions should be sought in the class of stable distributions. Accordingly, the price dynamics of a risky asset should be described by the Levy process (see 
$[24 ; 25])$. Various parametric families of infinitely divisible distributions have been proposed for describing the returns distribution. Models based on Levy processes have gained the particular popularity in the last decade. Scientists and practitioners are interested in applying them to mathematical finance. This interest is due to the adequacy of Levy processes in describing the observed phenomena. Levi's processes allow simulating jumps, heavy tails and asymmetry of distributions. The use of Levy processes in finance has two characteristics. First, it is not possible to obtain explicit formulas even in the simplest cases in solving the problems of pricing derivatives and hedging tasks. Here numerical methods play an especially important role. Secondly, the market model, in which price dynamics is described by the Levy process, allows (as a rule) more than one martingale measure. The fair price of a derivative instrument is not determined unequivocally in such a market. There is a certain family of prices that do not allow arbitration. The problem of determining the upper and lower limits of fair prices, a certain price corridor arises. It seems appropriate to note the controversial notion of a "fair price" for volatile and emerging markets. The standard of accounting, based on the principle of fair value requires banks and other financial institutions to reassess the value of assets periodically. This standard is too vague. For example, he does not decipher what assessment of a trading platform (rating agency, insurance policy, etc.) can be considered as fair and which one cannot. In addition, the global financial crisis made it obvious: the financial situation of banks and financial intermediaries in countries where there was no requirement to record assets and liabilities at fair market was better than in countries where it was applied. For this reason, a number of international experts have proposed to abandon the practice of financial accounting at current market prices, i.e. considering their fair value. In our opinion, it is possible to use this concept in prices mathematical modeling only under conditions of developed and relatively stable markets.

In [24], it was shown that good results in describing the price dynamics of a risk asset are obtained using Meixner processes. Meixner density distribution has the following form:

$$
f(x ; \alpha, \beta, \delta, \mu)=\frac{(2 \cos (\beta / 2))^{2 \delta}}{2 \alpha \pi \Gamma(2 \delta)} \exp \left(\frac{\beta(x-\mu)}{\alpha}\right)\left|\Gamma\left(\delta+\frac{i x}{\alpha}\right)\right|^{2},
$$

where $\alpha>0,-\pi<\beta<\pi, \delta>0$, and $\mu$ - bias. 
Note, that the sum of independent random variables with Meixner distribution with parameters, $\beta, \delta, \mu$, also has Meixner distribution with parameters $\alpha, \beta, n \delta, n \mu$.

Selective estimation of distribution parameters can be made using either the method of moments or the maximum likelihood method.

In the first case, the parameters estimates are the solution of the equations system for the moments of distribution (with the replacement of the true moments by the sample ones):

$$
\begin{gathered}
\mathrm{E}=\mu+\alpha \delta(\beta / 2) ; \mathrm{V}=\frac{1}{2} \alpha^{2} \delta \cos ^{-2}(\beta / 2) ; \\
\mathrm{As}=\sin (\beta / 2) \cdot \sqrt{2 / \delta} ; \mathrm{Ex}=\frac{3-2 \cos ^{2}(\beta / 2)}{\delta} .
\end{gathered}
$$

The maximum likelihood method is implemented using numerical methods.

In [24], it was shown that the use of the Meixner distribution to describe the returns of world stock indices makes it possible to achieve high accuracy of approximation. As applied to the Russian market, Meixner distributions were considered in [25] with a similar result.

Meixner distributions have the property of infinite divisibility. All moments exist. The coefficient of kurtosis is positive for any valid parameters. Meixner distribution density decreases as

$$
|x|^{2 \delta-1} \exp (-b|x|)
$$

(with different constants in the positive and negative regions) at infinity.

The conclusions of Schutens in [24] about good results of the model using the Meixner distribution are confirmed by studies of the Russian stock market. For the Russian market, the parameters of the Meixner distribution were estimated for the three-year period preceding the crisis, and for the period from 2000 to 2017 . The following parameters values were obtained:

$\alpha=0,047 ; \beta=-0,379 ; \delta=0,239 ; \mu=0,004$

for the period 2004-2007;

$\alpha=0,069 ; \beta=-0,372 ; \delta=0,220 ; \mu=0,005$

for the period 2000-2017.

An important property of the model is its predictive ability. In order to accept the model with the Meixner distribution as qualitative and prognostically valuable, it has to be sufficiently stable with respect to small 
fluctuations of the initial data and relatively small shifts along the time axis.

Data analysis shows, the model with a normal distribution works better than the Meixner model (the normalization of returns is still observed) for 25-75 days range of time. With more than 200 days duration of the prognostic period, both models often do not correspond to the empirical distribution. Finally, for periods of 100-150 days, Meixner model works definitely better than the classical model, allowing deviations from normality to be taken into account, when forming a financial risk management strategy.

The model based on the Meixner distribution was first proposed by Schutens [26] for analyzing European and American indices. Note that the use of such models (instead of classic ones) for the Russian market is more significant. For example, for the DJA index, the Meixner distribution is very close to normal, both theoretical distributions are consistent with empirical data. For the RTS and MICEX in-dexes, this is no longer the case due to the high costs of operations.

Reduction of transaction costs contributes to the improvement of the system responsible for financial imbalances management. The choice of financial organizations as an object of system imbalances management is aimed at enhancing their sustainability based on a combination of measures increasing prudential capital requirements and liquidity, improving supervisory practices at the micro and macro levels and imposing restrictions on the size, diversity of activities and risk levels. In turn, regulatory requirements for the size of own capital, its sufficiency and liquidity include following measures: a) improving the quality and transparency of banking capital; b) the introduction of the maximum permissible leverage ratio (capital / assets); c) the creation of countercyclical capital reserves; d) strengthening countercyclical requirements for capital adequacy, taking into account risk (including operations with derivatives (derivatives) and securitization); e) transition to the formation of reserves for compensation of loans losses, taking into account the phases of the credit cycle; e) the introduction of global liquidity ratios.

The implementation of the proposed measures will contribute to the improvement of the pricing policy of financial institutions and streamline the formation of prices for derivative financial instruments.

In classical Black-Scholes theory, the price of derivative instruments is determined using replicating strategies (portfolios). In the case of a market 
with transaction costs, accurate replication may be too expensive. In this case, exact replication is replaced by the approximate one obtained as a result of solving the problem of stochastic control by dynamic programming methods. The practical determination of the price with this approach turns out to be difficult even when the price dynamics is described by the Brownian motion (see [27]). Methods for calculating derivatives prices on the market with transaction costs can be obtained, as a rule, by narrowing the class of acceptable strategies. For example, if portfolio restructuring in the classical market with proportional transaction costs is allowed only through fixed time intervals, the Leland amendment [28] can be used.

The market with transaction costs, as a rule, is not complete. Full hedging of derivatives in an incomplete market is not feasible. To determine the price of derivative instrument, we use the upper and lower hedges, which allow us to estimate the range in which the price of the instrument should be located. The market in which the dynamics is determined by the Levy process, is not complete even in the absence of transaction costs. In such a market there is a family of martingale measures. The current price of a derivative instrument, calculated as the discounted expectation of its price on time horizon $\mathrm{T}$, does not allow arbitrage. Thus, there is a family of fair prices. The task of determining the boundaries of this family is difficult and far from the final decision.

An efficient algorithm for obtaining price boundaries in the case of a multi-period market was proposed in $[29 ; 30]$. Investment decisions can be made at time points $n=0,1,2, \ldots, N$ in a multi-period market. The main results in $[29 ; 30]$ were obtained for the classical market with independent increments of profitability. Nevertheless, some important results from [30] can be transferred to the market, the dynamics of which is described by the Meixner process. Note that with some reservations, these results can also be used in models where the increments of profitability are not independent [31].

We describe a model for determining the boundaries of prices of derivative instruments in markets with transaction costs, based on the method of stochastic dominance.

Consider a multi-period market with three types of assets: a risk-free asset (account), risky asset, and cash-settled call option of a European type for a risky asset with an execution price $K$ and a maturity date $T$. We denote 
by $\mathrm{r}$ the risk-free interest rate and by $\varepsilon$ - the brokerage commission. In order to acquire $\mathrm{g}$ shares of a risky asset at the time $\mathrm{t}$, it is required to withdraw the amount $b=(1+\varepsilon) g S_{t}$ from the account. By withdrawing the amount $\mathrm{b}$ from the account, you can purchase $g=(1-\varepsilon) b / S_{t}$ units of a risky asset. The sale (or short sale) of a risky asset unit increases the bill by $g=(1-\varepsilon) S_{t}$ . We assume the expected gross yield of a risky asset $\mu$ does not change from period to period and exceeds the risk-free rate $r$. The investor (trader) acts on the market, maximizing the utility function $U(x)$. It is assumed that $U(x)$ - increasing concave function.

Using the method proposed in [30], we define the upper and lower boundaries of options with the following property: transactions at any price outside the range obtained cannot be carried out in arbitrage-free market.

The investor's cash at the time is distributed between shares and bonds: he has $y_{t} / S_{t}$ shares (that is, cash is in shares) and $x_{t}$ of cash in bonds. An investor can redistribute his money between stocks and bonds, increasing (or reducing) his her investments in stocks from $y_{t}$ to $y_{t}+v_{t}$, reducing (or increasing) investments in bonds from $x_{t}$ to

$$
x_{t}-v_{t}-\max \left[\varepsilon v_{t} ;-\varepsilon v_{t}\right] \text {. }
$$

Taking into account the investment decision vt, the dynamics of investments in bonds and in shares are respectively as follows $(t<T)$ :

$$
\begin{gathered}
x_{t+1}=\left\{x_{t}-v_{t}-\max \left[\varepsilon v_{t} ;-\varepsilon v_{t}\right]\right\}(1+r) ; \\
y_{t+1}=\left(y_{t}+v_{t}\right) S_{t+1} / S_{t} .
\end{gathered}
$$

On the final trading day $\mathrm{T}$, equity investments are liquidated: $v_{T}=-y_{T}$. The net cash value of the investor will amount

$$
W_{T}=x_{T}+y_{T}-\max \left[-\varepsilon y_{T}, \varepsilon y_{T}\right] \text {. }
$$

Consider the upper and lower estimates for the price limit of a European call option with a underlying asset in the form of a stock with a strike price $K$ and execution date $T$.

At any time t, prior to the expiration time, the sale price of the option will be limited above by the value

$$
\bar{C}_{t}=\frac{1+\varepsilon}{1-\varepsilon} \frac{E\left[\left(S_{T}-K\right)^{+} \mid S_{t}\right]}{(1+\mu)^{T-t}} .
$$

To obtain this estimate, the integral is calculated 


$$
E\left[\left(S_{T}-K\right)^{+} \mid S_{t}\right]=\int_{\ln \frac{K}{S_{t}}}^{+\infty}\left(S_{t} e^{x}-K\right) \varphi_{T-t}(x) d x,
$$

Where $\varphi_{T-t}(x)$ is density distribution of the logarithmic yield for the period $T-t$.

The lower bound is obtained by reverse induction. For the moment $T$ we have

$$
\underline{C}_{T}=\left(S_{T}-K\right)^{+}
$$

For the moment $t<T$, the estimate is obtained as follows:

$$
\underline{C}_{t}=\frac{E\left[\underline{C}_{t+1} \mid S_{t}, S_{t+1} \leq Z_{t}\right]}{1+r},
$$

where the value $x$ is determined from the equation

$$
E\left[S_{t+1} \mid S_{t}, S_{t+1} \leq Z_{t}\right]=\frac{1-\varepsilon}{1+\varepsilon}(1+r) S_{t} .
$$

Conditional expectation is calculated just as it is done when calculating the upper limit. The equation can first be converted to

$$
E\left[e^{x} \mid x \leq \ln q\right]=\frac{1-\varepsilon}{1+\varepsilon}(1+r),
$$

where $q=\frac{Z_{t}}{S_{t}}$, and $x=\frac{S_{t+1}}{S_{t}}$ is daily yield. Now to solve the equation

$$
\frac{\int_{-\infty}^{\ln q} e^{x} \varphi(x) d x}{\int_{-\infty}^{q} \varphi(x) d x}=\frac{1-\varepsilon}{1+\varepsilon}(1+r),
$$

where $\varphi(x)$ is the density of yeild distribution per unit of time, numerical methods can be applied.

The analysis showed when assessing risks with use of the Meixner distribution, the most strict upper limit of the arbitrage-free option price is less than the weighted average price of transactions, i.e. option is overvalued by the market. At the same time, the bid-ask spread exceeds the estimated upper limit, so it is not possible to realize this "arbitrage" opportunity. It is also interesting to note the price calculated by the Black-Scholes formula lies very close to the most rigorous assessment of the upper price limit (and also, of course, lies within the bid-ask spread). 
In our opinion, the use of Meixner distribution and the method of stochastic dominance to evaluate the value of assets will help manage market risks.

In general, to assess price risk and potential transaction costs, a financial institution needs to monitor and manage stock risk. Price risk monitoring is carried out through regular analysis of market conditions for individual types of assets. Price risk management taking into account transactional risks is based on the observance of limits and related procedures. It is quite typical, that the following types of limits contribute to the limitation of possible losses from price risk:

stop-loss - determines the maximum amount of losses from lowering prices for this instrument. It determines level of prices falling where it is necessary to make a decision on the termination of further operations;

stop out - sets the amount of maximum losses for a given type of asset, liability, portfolio as a whole. Upon receiving a loss, equal to the amount of the limit, all operations are terminated, and a decision is taken on further actions, for example, the sale of this asset or its position restructuring;

take profit - shows the size of the maximum price increase for this instrument, it is used when the possible price maximum is achieved, from the point of view of analysis, to ensure the financial security of the bank against a possible sharp decrease in the value of the instrument;

take out - is an addition to the take profit limit, it is established on a specific type of asset, liability, or financial portfolio as a whole.

An effective way to manage price risk is use of counter transactions with available derivative financial instruments, including index futures. For the purpose of hedging price risk, considered above methodology is used.

The real progress of financial risk management, according to the IMF, the Financial Stability Board (FSB), the G-20 group of countries, and the Basel Committee on Banking Supervision (BCBS) should be achieved in five key directions:

- the formation of a regulatory system providing each market participant with legitimate and equal chances for successful operations;

- increasing the effectiveness of state control;

- creation of harmonious mechanisms for resolving problems of financial institutions at the national and transboundary level;

- formation of a comprehensive macroprudential system;

- expansion of the approach to financial regulation, which should be focused on risks of individual institutions and the financial system as a whole. 
Effective risk management includes the use of mathematical modeling and forecasting methods. The proposed method of pricing policies formation ensures financial stability to public and private institutions and makes their stock markets participation safer.

It also worth, while using the European Union experience in their methods of strengthening their efforts for cooperation in the aim of improving the level of leaving. For example, the Republic of Ireland was a very poor country in the 1950's that relied heavily its agricultural sector which had slow growth. The country contained the characteristics of a closed economy of protectionism and self-sufficiency. The over dependence and reliance of one economic sector and the lack of trade resulted in a stagnant economy which reflects the situation of Belarus and Kyrgyzstan of the Eurasian Economic Union. In order to break the economic deadlock, Ireland's economy had to introduce many economic and finanial policies that would pave the way for economic development. These policies included the following:

- better access to loans and financial markets for commercial entities;

- courting of foreign investment;

- improved intergovernmental grants to new industries;

- tax relief for manufactured exported goods.

The tax relief facilitated major advances in the industrial sector, which was responsible for an overall economic growth of $23 \%$ by 1963 . This new strategy, resulted in $80 \%$ of investment coming through foreign capital by 1965. During the 1960's this attracted 350 new foreign companies. This help to raise employment with high earning jobs which also increased domestic demand. A critical factor of the Eurasian Economic Union is the free trade that will enable the development of involved countries. Without the EU membership, Ireland would be as little of interest as a country for investment. Similarly, an economic union for the Eurasian members may be a vital component in future development. A part of the development of the Irish economy was the mass turnover of public enterprises into the private sector. This 21 commercialization of state owned enterprises assisted in an increased efficiency of operations and general competition in the companies and their markets. Another important factor for the development of Ireland was the loosening of structural rigidities which includes trade unions, farming interests and government wage levels. O'Donnell [34], details this, as the government determined that moderate wage growth was important 
for international competitiveness and to achieve control of public finances. These factors along with free second level education were the foundation of the underdeveloped economy of the 1950's transforming into a developing economy of the 1960's and a developed economy by the 1990's.

\section{Conclusion}

The analysis of this research concludes that the Kazak index had a relatively weak relationship with the Moscow Index until 2007. Thereafter, the effects of the financial crisis impacted both indices resulting in them being highly correlated ever since. The correlation result reflects the results from the graphical analysis. Moreover, it is found that the Moscow index has a stronger relationship with external indices, including the DAX and the S\&P 500, when examining external influences. This may be a reflection of the high volume of exports going to European countries. As can be seen in Figure 13 in the Appendix, Germany is the second largest recipient of Russian goods. This may represent a contagion effect which may occur in European stock market and spread to the MCX stock market. At the same time, the KASE index may be more dependent on the MCX, due to the large number of exports flowing to Russia. The analysis shows that the two Eurasia countries have a high dependence on the production of raw materials, while the S\&P500 is a diversified index including a strong mix of technology, construction, pharmaceutical and energy companies.

Thus, the integration of the countries in the new Eurasian Union will have to develop harmonized economic policy in order to attract new growth into economic sectors, backed by reasonable financial risk management and harmonized principles of cooperation. The development of new branches along with a deregulation will stimulate growth. The research that is presented in this analysis can be further developed by some econometric modelling to determine the short run and long run relationships of the KASE and MCX, and also to find which index leads the other. The research found that both indexes still rely heavily on the production of raw materials and depends on the price movements of commodities more than any other factor. A further study could find the relationship between the KASE market with the oil and copper price movements. This could determine whether the KASE index depends also on the price movements of commodities more than any other factor. 
Finally, it is worth, while mentioning, that EAEU member face the changing world and possess the power of making it better. Thus, it is appropriate to take into consideration international experience in strengthening efforts for solving mutual problems and meeting challenges.

\section{References:}

1. Shuvalov I. (2014). Eurasian Economic Union to have common currency in 5-10 years (TASS). 2014; Available at: http://tass.com/economy/742323 (accessed $16^{\text {th }}$ August 2018).

2. Gavin M. The Stock Market and Exchange Rate Dynamics. Journal of International Money and Finance, 1989; 181-200.

3. Jochum, C., Kirchgassner, G., Platek, M. A long-run relationship between Eastern European stock markets? Cointegration and the 1997/98 crisis in emerging markets. Review of World Economics, 1999; 454-479.

4. Rockinger, M. A Time Varying Parameter Model to Test for Predictability and Integration in Stock Markets of Transition Economies. 2000; C.E.P.R. Discussion Papers.

5. Yang, J., Hsiao, C., Wan, Z. The Emerging Market Crisis and Stock Market Linkages: Further Evidence. Journal of Applied Econometrics, 2006; 727-744.

6. Nieh C-C, Lee C-F. Dynamic Relationship between Stock Prices and Exchanges. 2001; 477-490.

7. Kuzmin, A. Rxchange Rate Modeling: The Case of Ruble. Munich Personal RePEc Archive, 2015; 39-41.

8. Griffin J., Stulz M., International Competition and Exchange Rates Shocks: A Cross-Country Industry Analysis of Stock Returns. Oxford University Press for Society for Financial Studies, 2001; 21.

9. Sberbank. Credit Ratings. 2017; [ONLINE] Available at http://www.sberbank. com/investor-relations/debt-profile/credit-ratings (accessed, 16 August 2018).

10. Treanor J. The 2010 'flash crash': how it unfolded (The Guardian), 2015. [ONLINE]. Available at: https://www.theguardian.com/business/2015/apr/22/2010flash-crash-new-york-stock-exchange-unfolded (accessed, 16 August 2018).

11. Riley C. Oil prices slide to 7-month low (CNN). 2012. [ONLINE]. Available at: http://money.cnn.com/2012/05/23/investing/oil-prices/index.htm (accessed 16August 2018).

12. Slav I. Russia Tops World's Biggest Oil Producers List (Oilprice.com). 2017. [ONLINE]. Available at: https://oilprice.com/Latest-Energy-News/World-News/ Russia-Tops-Worlds-Biggest-Oil-Producers-List.html (accessed 16 August 2018).

13. Cbonds. S\&P Global Ratings downgrades Local Currency LT credit rating of Halyk Bank to "BB" (Cbonds). 2017. [ONLINE]. Available at: http://cbonds.com/ news/item/921307 (accessed 16 August 2018).

14. Kawa L. U.S. Stock Buybacks are Plunging (Bloomberg). 2017. [ONLINE]. Available at: https://www.bloomberg.com/news/articles/2017-08-14/corporateamerica-isn-t-buying-back-shares-the-way-it-used-to (accessed 16 August 2018).

15. Byrne J.-A. US companies spent $\$ 4$ T buying back their own stock (NYPost). 2017. [ONLINE]. Available at: https://nypost.com/2017/08/19/us-companiesspent-4t-buying-back-their-own-stock/ (accessed 16 August 2018). 
16. Valetkevitch C. US Stocks-Dow off to worst January start ever as China fears grow (Reuters). 2016. [ONLINE]. Available at: https://www.reuters.com/ article/us-usa-stocks/dow-sp-off-to-worst-four-day-jan-start-ever-as-china-fearsgrow-idUSKBN0UL1BD20160107 (accessed 16 August 2018).

17. Dean M., Livesey B. S\&P Places 15 Euro Nations on Warning for Credit Downgrade (Bloomberg). 2011. [ONLINE]. Available at: https://www.bloomberg. com/news/articles/2011-12-05/s-p-said-to-place-all-17-euro-nations-ondowngrade-watch-over-debt-crisis (accessed 16 August 2018).

18. Wearden G. FTSE100 hits 15-month low as stock markets slide (the Guardian). 2014. [ONLINE]. Available at: https://www.theguardian.com/business/ live/2014/oct/15/uk-unemployment-wages-china-inflation-shire-business-live (accessed 16 August 2018).

19. Pisani B. What happened during the Aug 24 'flash crash' (CNBC). 2015. [ONLINE]. Available at: https://www.cnbc.com/2015/09/25/what-happenedduring-the-aug-24-flash-crash.html (accessed 16 August 2018).

20. Review of financial stability for 2010-2012. Bank of Russia Research and Information Department. Available at: //www.cbr.ru/today/publications_reports/fin-stab

21. Sornette, D. (2003). Why stock markets crash: critical events in complex financial systems. Princeton University Press, $448 \mathrm{p}$.

22. Siokis F.M. (2017). Financial markets during highly anxious time: multifractal fluctuations in asset returns. Fractals, 25(03), p. 1750032. Available at: doi: https://doi.org/10.1142/S0218348X17500323

23. Kharitonov V.V., Yezhov A.A. (Ed.) Econophysics. Moskva: MEPI, 2007, 624 p.

24. Shoutens W. Levy processes in finance. Pricing financial derivatives. John Wiley \& Sons, 2003, 170 p.

25. Borusyak K.K. The application of the Meixner model of the distribution of profitability of financial assets to the Russian stock market. - Mathematical methods for the analysis of financial time series: a collection of scientific articles (VB Gisin, AB Shapoval - ed.). Moskva: Finakademiya, 2008, 4-23.

26. Shoutens W. Meixner processes in finance. EURANDOM Report 2001-002. Eindhoven: EURANDOM, 2000, pp. 1-25.

27. Kabanov, Y., Safarian, M. Markets with transaction costs. Mathematical theory. Springer, 2009, $294 \mathrm{p}$.

28. Leland H. Option pricing and replication with transaction costs. - J. Finance, 1985, No. 5(40), pp. 1283-1301.

29. Constantinides G.M. Multiperiod consumption and investment behavior with convex transactions costs. Management Science, 1979, Issue 11 (25), pp. 1127-1137.

30. Constantinides G.M., Perrakis S. Stochastic dominance, with proportional transaction costs. Journal of Economic Dynamics \& Control, 2002, № 26, pp. 1323-1352.

31. Gisin V. Markov A. Asset Pricing in a Fractional Market Under Transaction Costs. In: Market Risk and Financial Markets Modeling. Springer, Berlin, Heidelberg, 2012. 47-56.

32. O'Donnell R. (1998). Ireland's economic transformation. Center for West European Studies, WP № 2 Dec., pp. 1-26. Available at: http://aei.pitt.edu/27/1/Odonnell.pdf 